\title{
Exposure-survival analyses of pazopanib in renal cell carcinoma and soft tissue sarcoma patients: opportunities for dose optimization
}

\author{
R. B. Verheijen ${ }^{1}$ L. E. Swart ${ }^{1}$ J. H. Beijnen ${ }^{1,2} \cdot$ J. H. M. Schellens ${ }^{2,3}$ \\ A. D. R. Huitema ${ }^{1,4} \cdot$ N. Steeghs ${ }^{3}$
}

Received: 13 June 2017 / Accepted: 13 October 2017 / Published online: 19 October 2017

(C) The Author(s) 2017. This article is an open access publication

\begin{abstract}
Background Pazopanib is an angiogenesis inhibitor approved for the treatment of renal cell carcinoma and soft tissue sarcoma. Post hoc analysis of a clinical trial demonstrated a relationship between pazopanib trough concentrations $\left(\mathrm{C}_{\min }\right)$ and treatment efficacy. The aim of this study was to explore the pharmacokinetics and exposure-survival relationships of pazopanib in a real-world patient cohort.

Patients and methods Renal cell cancer and soft tissue sarcoma patients who had at least one pazopanib plasma concentration available were included. Using calculated $\mathrm{C}_{\text {min }}$ values and a threshold of $>20 \mathrm{mg} / \mathrm{L}$, univariate and multivariate exposure-survival analyses were performed.

Results Sixty-one patients were included, of which $16.4 \%$ were underexposed (mean $\mathrm{C}_{\text {min }}<20 \mathrm{mg} / \mathrm{L}$ ) using the $800 \mathrm{mg}$ fixed-dosed schedule. In univariate analysis $\mathrm{C}_{\min }>20 \mathrm{mg} / \mathrm{L}$ was related to longer progression free survival in renal cell cancer patients ( 34.1 vs. 12.5 weeks, $n=35, p=0.027$ ) and the overall population ( 25.0 vs. 8.8 weeks, $n=61, p=0.012$ ), but not in the sarcoma subgroup (18.7 vs. 8.8 weeks, $n=26$, $p=0.142$ ). In multivariate analysis $\mathrm{C}_{\min }>20 \mathrm{mg} / \mathrm{L}$ was associated with hazard ratios of $0.25(p=0.021)$ in renal cancer,
\end{abstract}

R. B. Verheijen

r.verheijen@nki.nl

1 Department of Pharmacy and Pharmacology, The Netherlands Cancer Institute - Antoni van Leeuwenhoek, Louwesweg 6, 1066 EC Amsterdam, The Netherlands

2 Department of Pharmaceutical Sciences, Utrecht University, Utrecht, The Netherlands

3 Department of Medical Oncology and Clinical Pharmacology, The Netherlands Cancer Institute - Antoni van Leeuwenhoek, Amsterdam, The Netherlands

4 Department of Clinical Pharmacy, University Medical Center Utrecht, Utrecht University, Utrecht, The Netherlands $0.12(p=0.011)$ in sarcoma and $0.38(p=0.017)$ in a pooled analysis.

Conclusion This study confirms that pazopanib $\mathrm{C}_{\min }>20 \mathrm{mg} / \mathrm{L}$ relates to better progression free survival in renal cancer and points towards a similar trend in sarcoma patients. $\mathrm{C}_{\min }$ monitoring of pazopanib can help identify patients with low $\mathrm{C}_{\min }$ for whom individualized treatment at a higher dose may be appropriate.

Keywords Pazopanib $\cdot$ Renal cell carcinoma $\cdot$ Soft tissue sarcoma $\cdot$ Pharmacokinetics $\cdot$ Dose optimization . Personalized medicine

\section{Introduction}

Pazopanib is an angiogenesis inhibitor, targeting the vascular endothelial growth factor receptor (VEGFR)-1,2,3, platelet derived growth factor receptor (PDGFR) $\alpha / \beta$, fibroblast growth factor receptor and the stem cell receptor/ c-Kit [1, 2].

Pazopanib increased progression free survival in renal cell carcinoma and in soft tissue sarcoma compared to placebo, resulting in market approval for both tumor types by the Food and Drug Administration and European Medicine Agency [3, 4]. A retrospective analysis from clinical trial data showed an increased median progression free survival in patients with pazopanib plasma trough concentrations $\left(C_{\text {min }}\right) \geq 20.5 \mathrm{mg} / \mathrm{L}$ compared to patients with lower concentrations (52.0 vs. 19.6 weeks, $n=177, p=0.004$ ) [5].

Pazopanib has a complex pharmacokinetic profile, described by low, non-linear and time-dependent bioavailability and large inter-individual variability [6-9]. This results in a subset of patients receiving less than optimal exposure [5]. It has been estimated in clinical trials that on 
the approved $800 \mathrm{mg}$ dose, approximately $20 \%$ of patients may not reach the $>20 \mathrm{mg} / \mathrm{L}$ threshold [5].

In routine clinical care pharmacokinetic variability may be even greater, as patients are likely to have more comorbidities and concomitant medication, may be older, have impaired renal or hepatic function and have suboptimal therapy adherence [10]. In particular the elderly are known to be underrepresented in clinical trials [11]. Moreover, it has been reported that only $39.0 \%$ of renal cancer patients treated with targeted therapies in routine clinical practice would be eligible for enrolment in the pivotal phase III trials of their respective therapy [12].

The above underscores the need for exploration of the proportion of patients that risk suboptimal efficacy due to low exposure in real-word patient cohorts. Especially, since it has been shown that increasing the pazopanib dose based on a low $\mathrm{C}_{\min }$ is a feasible and safe option that could lead to improved treatment outcomes [13].

We now report an observational unselected cohort study in renal cell carcinoma and soft tissue sarcoma patients to identify the number of patients at risk of suboptimal treatment due to low exposure. Additionally, we perform exposure-response and exposure-toxicity analyses and explore if patient characteristics could predict the occurrence of low pazopanib $\mathrm{C}_{\text {min }}$.

\section{Materials and methods}

\section{Patient inclusion and data collection}

An observational study was performed in the outpatient clinic of the Netherlands Cancer Institute, Amsterdam, The Netherlands. Plasma sampling for concentration monitoring was performed as part of routine care in all patients treated with pazopanib at this hospital (however, no dose increments above $800 \mathrm{mg}$ based on low $\mathrm{C}_{\min }$ were performed during the study period). In the current study, data from routine clinical care including pazopanib plasma concentrations were used retrospectively, which has been authorized in the institute.

Renal cell carcinoma and soft tissue sarcoma patients who received pazopanib treatment as part of standard of care and who had at least one pazopanib plasma concentration measured were included.

Visits were planned according to standard of care in accordance with respective treatment guidelines. Clinical characteristics including demographic data, medical history, pazopanib dose, treatment duration, reason for discontinuation and progression free survival were collected retrospectively from medical records.

\section{Pharmacokinetics}

Blood samples were drawn at routinely scheduled visits to the outpatient clinic. Date and time of last intake of pazopanib dose and the time of blood sampling were recorded. Plasma pazopanib levels were determined using a validated liquid chromatography tandem mass spectrometry assay [14]. $\mathrm{C}_{\min }$ values were calculated based on the measured concentration and interval between last ingested dose and sample time using the algorithm developed previously for imatinib [15]. Samples drawn before $T_{\max }(2 \mathrm{~h})$ [8] or more than $24 \mathrm{~h}$ after the last dose were excluded from the analysis.

Relationships between $\mathrm{C}_{\min }$ and available patient characteristics were explored, including tumor type, age, weight, gender, (lowest) pazopanib dose and World Health Origination (WHO) performance status. Binary variables were tested using two-sided $t$ tests, categorical variables using analysis of variance, numerical variables using linear regression. $p$ values $<0.05$ were considered significant. All statistical analyses were performed in R 3.3.1 [16].

\section{Exposure-survival analysis}

For the purpose of exposure-survival analyses the mean of all available $\mathrm{C}_{\min }$ levels per patient was used as parameter for exposure during the entire treatment period, as described previously [13]. Progression free survival of patients with a mean $\mathrm{C}_{\min }$ above or below the pharmacokinetic threshold of $>20 \mathrm{mg} / \mathrm{L}$ was analyzed in univariate (Kaplan-Meier analysis plus log-rank test) and multivariate analyses using Cox regression. In multivariate analysis performances status, (lowest) pazopanib dose, number of prior lines of therapy, age and sex were included as covariates. For the exposure-survival analyses in sarcoma, the tumor subtype (leiomyosarcoma, synovial sarcoma or other) was included as an additional covariate. Results are reported as hazard ratios plus $95 \%$ confidence intervals $(95 \% \mathrm{CI})$. A pooled analysis of all patients was also performed. Here, tumor type (renal cancer versus sarcoma) was also included in the multivariate Cox regression.

\section{Exposure-toxicity analysis}

Pharmacokinetic exposure was compared between patients who discontinued pazopanib therapy due to toxicity and those who did not. Both the average $\mathrm{C}_{\min }$ per patient and the last $\mathrm{C}_{\min }$ closest to the discontinuation event (due to toxicity or progressive disease) were analyzed. 


\section{Results}

\section{Evaluable patients}

From April 2013 to November 2016, 61 patients were included in the analysis, of whom 35 had renal cell carcinoma and 26 soft tissue sarcoma. A full overview of patient characteristics, including WHO performance status, pazopanib dose, previous lines of therapy, age, weight, sex and number of samples is given in Table 1.

The subtypes of the sarcoma patients included leiomyosarcoma $(n=12)$, synovial sarcoma $(n=6)$, pleomorphic sarcoma $(n=2)$, epithelioid sarcoma, malignant peripheral nerve sheath tumor, angiosarcoma, solitary fibrous tumor, myxofibrosarcoma and undifferentiated spindle cell sarcoma (all $n=1)$.

\section{Pharmacokinetics}

In total, 227 plasma samples were included. Overall, a mean (range) of 4 (1-17) samples were available per patient, 3 (1-9) for the sarcoma and 4 (1-17) for the renal cancer patients. In aggregate, mean (coefficient of variation $(\mathrm{CV} \%)$ ) pazopanib $\mathrm{C}_{\min }$ was $28.1(39.7) \mathrm{mg} / \mathrm{L}$, ranging from 6.90 to $77.8 \mathrm{mg} / \mathrm{L}$. Median [range] sampling time was $6[1-44]$ months since start of therapy. With $5 \%$ of samples taken $<4$ weeks after start. Median interpatient variability (quantified as $\mathrm{CV} \%$ of the multiple $\mathrm{C}_{\text {min }}$ values per patient on the same dose) was $24.8 \%$.

An overview of the distribution of average $C_{\text {min }}$ per patients per tumor type is provided in Fig. 1 and Table 1. In renal cancer patients mean $(\mathrm{CV} \%) \mathrm{C}_{\text {min }}$ per patient was 26.9 (36.4) $\mathrm{mg} / \mathrm{L}$ compared to 31.9 (36.3) $\mathrm{mg} / \mathrm{L}$ in the sarcoma patients. The overall average $\mathrm{C}_{\min }$ per patient was $29.0(37.1) \mathrm{mg} / \mathrm{L}$.

Although $\mathrm{C}_{\min }$ was higher in sarcoma compared to renal cancer patients (Table 1), this difference was not statistically significant $(p=0.081)$. In renal cell carcinoma 6 $(17.1 \%)$ and in soft tissue sarcoma $4(15.4 \%)$ patients were underexposed (mean $\mathrm{C}_{\min }<20 \mathrm{mg} / \mathrm{L}$ ) using the $800 \mathrm{mg}$ fixed-dose schedule.

Of all explored clinical parameters, none were found to be significantly predictive of low pazopanib $\mathrm{C}_{\min }$ except gender in renal cell cancer patients and age in sarcoma patients. Female sex was associated with a higher $\mathrm{C}_{\min }$ (mean (CV\%) of 33.1 (32.5) $\mathrm{mg} / \mathrm{L}$ versus 23.2 (30.1) $p=0.005)$. Of the six renal cancer patients with low $\mathrm{C}_{\min }$ only one was female.

In sarcoma patients, linear regression indicated that patients with higher age had lower $\mathrm{C}_{\min }$ and was associated with a slope of -0.454 and Pearson's $r$ of -0.414 $(p=0.035)$.

Table 1 Characteristics of included patients

\begin{tabular}{|c|c|c|c|}
\hline & Renal cell carcinoma & Soft tissue sarcoma & Overall \\
\hline Patients $(n)$ & 35 & 26 & 61 \\
\hline \multicolumn{4}{|l|}{ Gender $(n(\%))$} \\
\hline Male & $22(62.9)$ & $14(53.8)$ & $36(59.0)$ \\
\hline Female & $13(37.1)$ & $12(46.2)$ & $25(41.0)$ \\
\hline Age (mean (range)) & $62(45-77)$ & $61(32-91)$ & $61(32-91)$ \\
\hline Weight (mean (CV\%)) & $84(23.1)$ & $77(17.5)$ & $81(21.6)$ \\
\hline \multicolumn{4}{|l|}{ Performance status ( $n(\%))$} \\
\hline 0 & $13(37.1)$ & $11(42.3)$ & $24(39.3)$ \\
\hline 1 & $16(45.7)$ & $14(53.8)$ & $30(49.2)$ \\
\hline 2 & $6(17.1)$ & $1(3.8)$ & $7(11.5)$ \\
\hline \multicolumn{4}{|l|}{ Pazopanib dose $(n(\%))^{*}$} \\
\hline $200 \mathrm{mg}$ & $3(8.6)$ & $1(3.8)$ & $4(6.6)$ \\
\hline $400 \mathrm{mg}$ & $5(14.3)$ & $2(7.7)$ & $7(11.5)$ \\
\hline $600 \mathrm{mg}$ & $6(17.1)$ & $2(7.7)$ & $8(13.1)$ \\
\hline $800 \mathrm{mg}$ & $21(60.0)$ & $21(80.8)$ & $42(68.9)$ \\
\hline Previous lines of systemic therapy (median (range)) & $1(1-4)$ & $1(0-2)$ & $1(0-4)$ \\
\hline Number of samples $(n)$ & 151 & 76 & 227 \\
\hline Samples per patients (mean (range)) & $4(1-17)$ & $3(1-9)$ & $4(1-17)$ \\
\hline Mean $(\mathrm{CV} \%) \mathrm{C}_{\min }$ per patient $(\mathrm{mg} / \mathrm{L})$ & $26.9(36.4)$ & $31.9(36.3)$ & $29.0(37.1)$ \\
\hline Patients with mean $\mathrm{C}_{\min }<20 \mathrm{mg} / \mathrm{L}(n(\%))$ & $6(17.1)$ & $4(15.4)$ & $10(16.4)$ \\
\hline
\end{tabular}

$C_{\min }$ Pazopanib trough level/minimum concentration, $C V \%$ coefficient of variation

*Lowest dose per patient 

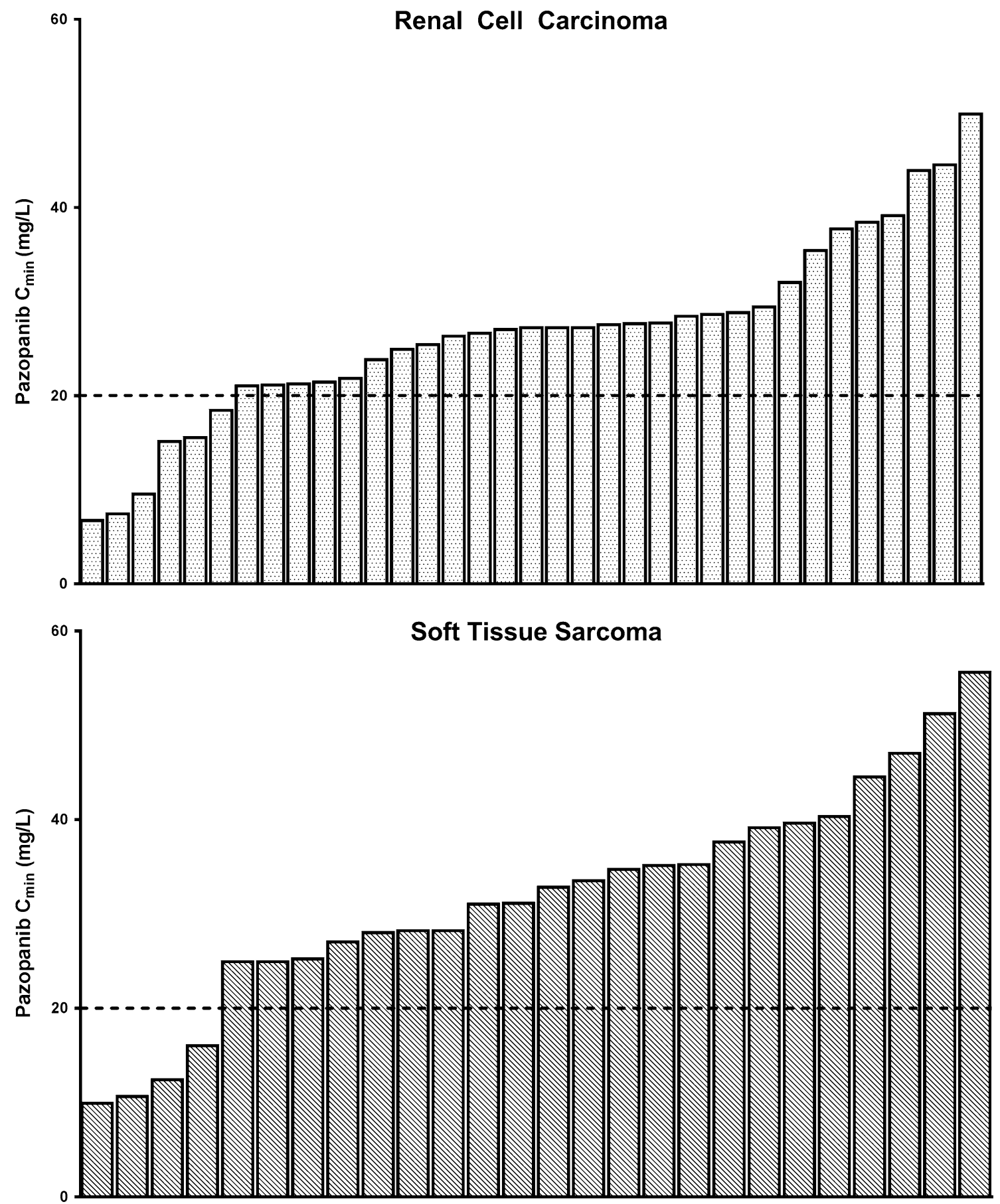

Fig. 1 Distribution of the mean calculated pazopanib $C_{\min }$ per patient for renal cell carcinoma $n=35$ (upper panel) and soft tissue sarcoma patients $n=26$ (lower panel). The dotted line indicates the threshold

\section{Exposure-survival analysis}

In renal cell carcinoma, $\mathrm{C}_{\min }>20 \mathrm{mg} / \mathrm{L}$ was significantly related to improved progression free survival in univariate analysis ( $p=0.027$, see Fig. 2 and Table 2). Median of $20 \mathrm{mg} / \mathrm{L}$. In renal cell carcinoma $6(17.1 \%)$ of patients and in soft tissue sarcoma $4(15.4 \%)$ of patients seem underexposed using the $800 \mathrm{mg}$ fixed-dosed schedule

progression free survival was 34.1 weeks for patients with high and 12.5 weeks for patients with low exposure.

In multivariate analysis, $C_{\min }$ above or below $20 \mathrm{mg} / \mathrm{L}$ resulted in a hazard ratio of 0.25 (95\% CI $0.076-0.81$, 


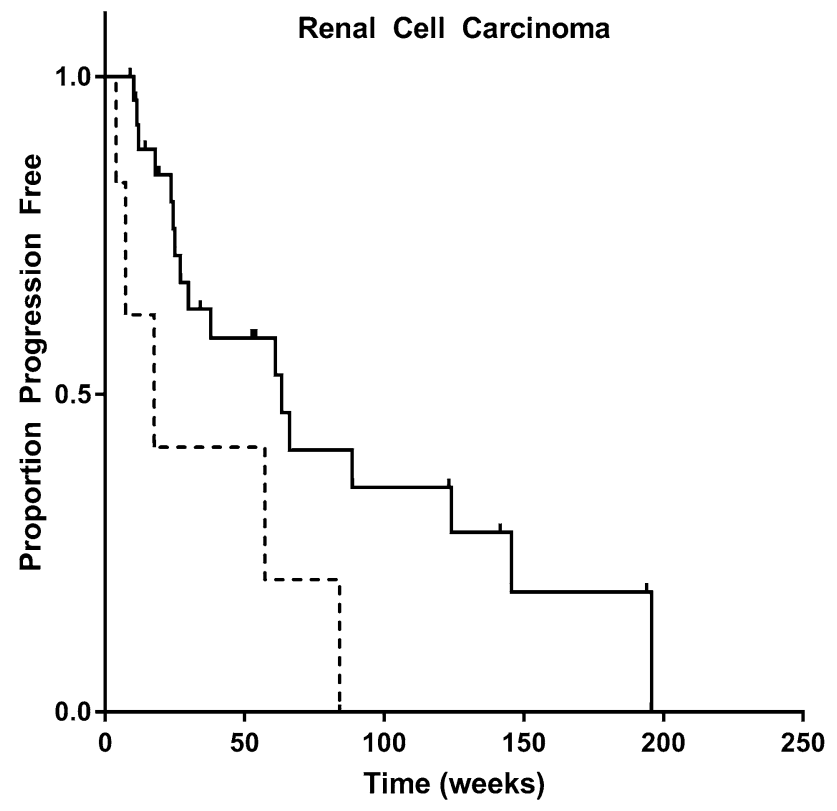

Fig. 2 Kaplan-Meier plot of progression free survival (weeks) for renal cell carcinoma patients with an average $C_{\min }$ above $(n=29$, solid line) or below ( $n=6$, dashed line) the exposure target of $>20 \mathrm{mg} / \mathrm{L}$. Median progression free survival was 34.1 weeks for patients with high and 12.5 weeks for patients with low exposure, $p=0.027$ (log-rank test)

$p=0.021)$. Female gender was also significantly related to increased progression free survival $(p=0.008)$.

In soft tissue sarcoma, median progression free survival was 18.7 weeks for patients with high and 8.8 weeks for patients with low $\mathrm{C}_{\min }(p=0.142, \log$-rank test, see Fig. 3; Table 2). In Cox regression, $\mathrm{C}_{\min }>20 \mathrm{mg} / \mathrm{L}$ was significantly related to progression free survival and associated with an hazard ratio of 0.12 (95\% CI 0.024-0.61, $p=0.011)$. In the sarcoma subgroup, worse performance status $(p=0.035)$ and lower age $(p=0.017)$ were also associated with shorter progression free survival.
In the pooled analysis, $\mathrm{C}_{\min }>20 \mathrm{mg} / \mathrm{L}$ was related to improved survival in univariate analysis ( 25.0 vs. 8.8 weeks, $p=0.012$, see Fig. 4 and Table 2). Here, multivariate analysis resulted in a hazard ratio of 0.38 (95\% CI 0.17-0.92, $p=0.017$ ) for $\mathrm{C}_{\min }>20 \mathrm{mg} / \mathrm{L}$. Worse WHO performance status and sarcoma as tumor type were also both associated with worse treatment outcome in the Cox model, $p=0.004$ and $p<0.001$, respectively.

An overview of the main univariate and multivariate exposure-survival outcomes is provided in Table 2.

\section{Exposure-toxicity analysis}

Of the 61 included patients, 44 discontinued treatment due to progressive disease and 5 due to toxicity. Reasons for discontinuation included, hepatotoxicity, hypertension, pancreatitis, dyspnea and multiple grade 2 toxicities (all $n=1$ ). Mean $\mathrm{C}_{\min }$ was $37.3 \mathrm{mg} / \mathrm{L}$ in those who discontinued due to toxicity, compared to $27.5 \mathrm{mg} / \mathrm{L}$ in those had experienced progressive disease. However, this difference was not statistically significant $(p=0.176)$. Mean $(\mathrm{CV} \%)$ last $\mathrm{C}_{\min }$ (the last available sample) was 37.7 (36.4) $\mathrm{mg} / \mathrm{L}$ compared to 26.4 (46.9) $\mathrm{mg} / \mathrm{L}(p=0.177)$.

\section{Discussion}

Pazopanib is administered at a fixed $800 \mathrm{mg}$ dose, which is only adjusted in case of severe toxicity. Yet, based on the available data this may lead to suboptimal treatment outcomes in a subset of patients [5]. We now show in an unselected cohort that approximately $16.4 \%$ of patients is underexposed using the pazopanib fixed-dosing schedule applying the predefined $\mathrm{C}_{\min }$ target of $>20 \mathrm{mg} / \mathrm{L}$ (Fig. 1, Table 1).

No clinical characteristics, except for gender and age were found to be significantly related to pazopanib $\mathrm{C}_{\min }$. In general, the ability of clinical characteristics to predict which patients experienced low $\mathrm{C}_{\min }$ was limited. This
Table 2 Overview of exposuresurvival analysis outcomes

\begin{tabular}{|c|c|c|c|}
\hline & Renal cell carcinoma & Soft tissue sarcoma & Overall \\
\hline Patients $(n)$ & 35 & 26 & 61 \\
\hline Median PFS (weeks) & 29.9 & 18.3 & 24.4 \\
\hline Median PFS $\mathrm{C}_{\min }>20 \mathrm{mg} / \mathrm{L}$ (weeks) & 34.1 & 18.7 & 25.0 \\
\hline Median PFS $\mathrm{C}_{\min }<20 \mathrm{mg} / \mathrm{L}$ (weeks) & 12.5 & 8.8 & 8.8 \\
\hline Univariate $p$ value (log-rank test) & 0.027 & 0.142 & 0.012 \\
\hline Hazard ratio $(95 \% \mathrm{CI})^{*}$ & $0.25(0.076-0.81)$ & $0.12(0.024-0.61)$ & $0.38(0.17-0.92)$ \\
\hline Multivariate $p$ value (Cox regression) & 0.021 & 0.011 & 0.017 \\
\hline
\end{tabular}

$C_{\text {min }}$ pazopanib trough level/minimum plasma concentration

$P F S$ progression free survival

95\% CI 95\% confidence interval

*Hazard ratios are based on the multivariate Cox regression analysis 


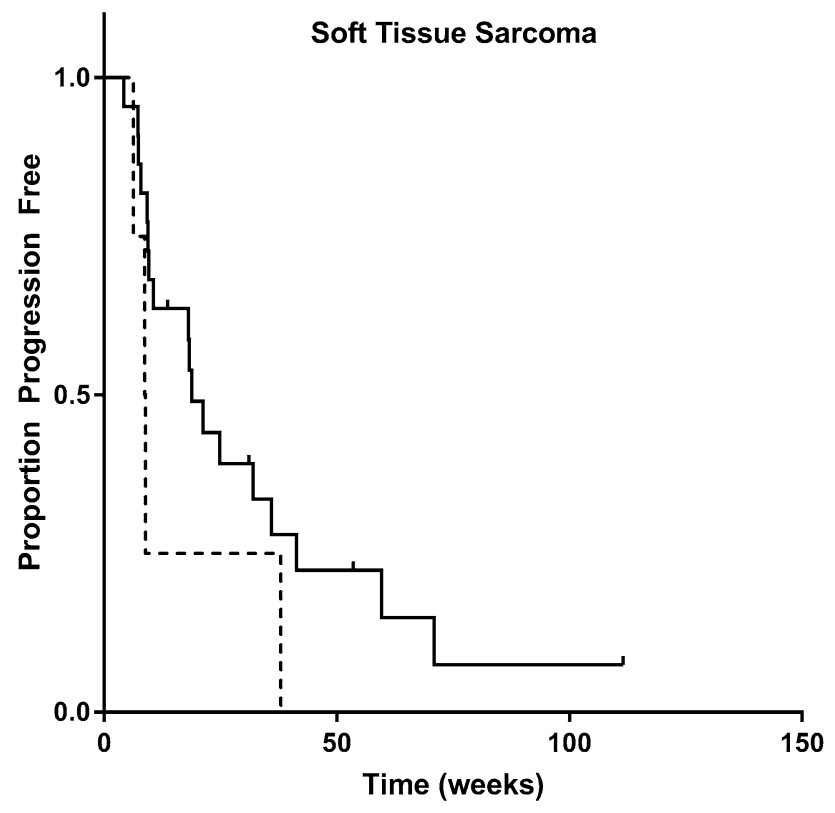

Fig. 3 Kaplan-Meier plot of progression free survival (weeks) for soft tissue sarcoma patients with an average $\mathrm{C}_{\min }$ above $(n=22$, solid line) or below ( $n=4$, dashed line) the exposure target of $>20 \mathrm{mg} / \mathrm{L}$. Median progression free survival was 18.7 weeks for patients with high and 8.80 weeks for patients with low exposure, $p=0.142$ (logrank test)

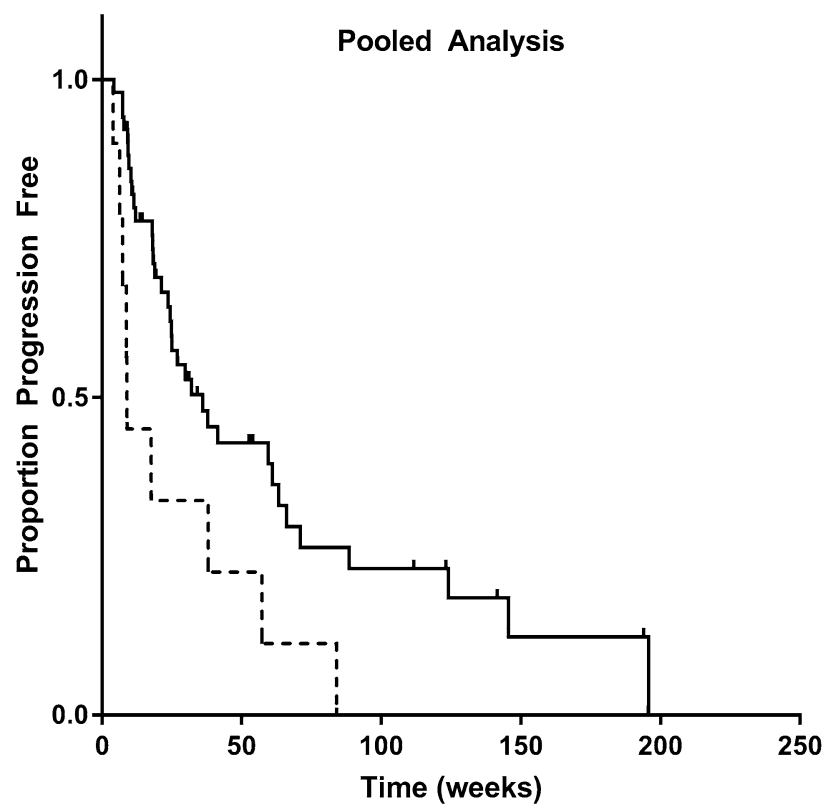

Fig. 4 Kaplan-Meier plot of progression free survival (weeks) in a pooled analysis of both renal cell carcinoma and soft tissue sarcoma patients with an average $\mathrm{C}_{\min }$ above $(n=51$, solid line) or below $(\mathrm{n}=10$, dashed line) the exposure target of $>20 \mathrm{mg} / \mathrm{L}$. Median progression free survival was 25.0 weeks for patients with high and 8.80 weeks for patients with low exposure, $p=0.012$ (log-rank test) underscores the relevance of routine pazopanib $\mathrm{C}_{\min }$ monitoring, as the subgroup at risk of lower efficacy cannot be identified employing clinical and demographic characteristics. Furthermore, the use of potential interacting medication is carefully monitored during routine care and, therefore, no effects of concomitantly used medication on PK exposure could be identified.

We demonstrate that in renal cancer patients $\mathrm{C}_{\min }>20 \mathrm{mg} / \mathrm{L}$ was significantly related to longer progression free survival (34.1 vs. 12.5 weeks, Table 2 and Fig. 2). Our data, therefore, confirm the findings of Suttle et al. in an independent patient cohort [5].

As no pharmacokinetic sampling was performed in the pivotal phase II trial in soft tissue sarcoma, [4] no pazopanib exposure threshold has been proposed yet in sarcoma. This is the first study to investigate a relationship between exposure and survival in sarcoma. However, possibly due to the limited size of the sarcoma subgroup in our cohort and the relatively lower effect size of pazopanib in sarcoma, our result did not reach statistical significance in univariate analysis (progression free survival of $18.7 \mathrm{vs.}$ 8.8 weeks, $p=0.142$, Fig. 3). Another possible explanation for the lack of significance in the univariate exposure-survival analysis could be the diversity of sarcoma subtypes. This heterogeneity may, therefore, explain differences in response rates and response duration between disease subtypes. However, in the multivariate analysis in sarcoma this difference in progression free survival for patients with $\mathrm{C}_{\min }>20 \mathrm{mg} / \mathrm{L}$ was statistically significant $(p=0.011)$.

In a pooled exposure-survival analysis (Fig. 4) higher pazopanib $\mathrm{C}_{\min }$ was significantly related to improved treatment outcomes. Furthermore, the existence of a similar exposure-response relationship is theoretically supported by the fact that efficacy of pazopanib is mediated by inhibition of the same target proteins (mainly VEGFR) in both tumor types. However, this exploratory pooled analysis should be interpreted with caution given the variability in sensitivity of the different tumor types.

Previous exposure-toxicity relationships have been reported for pazopanib related adverse events such as hepatotoxicity and hypertension and dose-limiting toxicity in pediatric patients $[5,17,18]$. Although not statistically significant, in this cohort we did find a numerically higher exposure in patients discontinuing due to toxicity $(n=5)$, this result was not statistically significant (37.3 vs. $27.5 \mathrm{mg} / \mathrm{L}, p=0.176$ ).

Drawbacks of this study are its retrospective nature, relatively limited number of patients in each tumor type and the heterogeneity in the availability and timing of plasma samples. Furthermore, not actual but calculated $\mathrm{C}_{\min }$ values (using an therapeutic drug monitoring algorithm as validated for imatinib) were used. However, this algorithm 
describes a general exponential decline in exposure with a specified plasma half-life and would, therefore, also be suitable for pazopanib.

Yet despite these limitations, it is the first pharmacokinetic study that reports exposure-survival and exposure-toxicity relationships for pazopanib in a real-world cohort of renal cell carcinoma and soft tissue sarcoma patients and identifies a subgroup of approximately $16.4 \%$ of patients which may benefit from individualized $\mathrm{C}_{\text {min }}$-guided pazopanib dosing.

Given the currently presented results and the previous work by Suttle et al [5], one could argue that a fixed dosing strategy for pazopanib is becoming increasingly inappropriate in the era of personalized medicine $[19,20]$. Recommendations for individualized dosing of pazopanib and other tyrosine kinase inhibitors have been made previously [21, 22]. Moreover, specifically for pazopanib the safety and feasibility of individualized dosing has been established in a prospective clinical trial [13].

Collectively, the current study and data available in the literature $[5,13]$ point towards the need to validate the strategy of individualized pazopanib dosing in a prospective randomized clinical trial.

\section{Conclusion}

In conclusion, at the currently approved fixed dose regimen a relevant subgroup of $16.4 \%$ of patients treated with pazopanib is underexposed in routine care and may be at risk of suboptimal treatment efficacy.

Our study further confirms that the previously established threshold of $\mathrm{C}_{\min }>20 \mathrm{mg} / \mathrm{L}$ is related to longer progression free survival in renal cell carcinoma patients (34.1 vs. 12.5 weeks, $n=35, p=0.027$ ). Moreover, exploratory analyses point towards a similar association of increased progression free survival with higher exposure in soft tissue sarcoma patients (18.7 vs. 8.8 weeks, $n=26, p=0.142$ ).

Plasma $\mathrm{C}_{\min }$ monitoring of pazopanib can help identify patients with low $\mathrm{C}_{\min }$ for whom treatment at a higher dose may be appropriate.

Acknowledgements N. Steeghs received an unrestricted grant (funding and study medication) from GlaxoSmithKline as Principal Investigator for an investigator initiated study with Pazopanib. Pazopanib is an asset of Novartis as of June 2015.

Funding No funding was received for this research.

\section{Compliance with ethical standards}

Conflict of interest R. B. Verheijen, L. E. Swart, J. H. Beijnen, J. H. M. Schellens and A. D. R. Huitema declare they have no conflicts of interest to disclose.

Ethical approval All procedures performed in this study involving human participants were in accordance with the ethical standards of the institutional and/or national research committee and with the 1964 Helsinki declaration and its later amendments or comparable ethical standards.

Informed consent For this type of retrospective study formal consent was not required.

Open Access This article is distributed under the terms of the Creative Commons Attribution 4.0 International License (http://creativecommons.org/licenses/by/4.0/), which permits unrestricted use, distribution, and reproduction in any medium, provided you give appropriate credit to the original author(s) and the source, provide a link to the Creative Commons license, and indicate if changes were made.

\section{References}

1. Kumar R, Knick VB, Rudolph SK et al (2007) Pharmacokineticpharmacodynamic correlation from mouse to human with pazopanib, a multikinase angiogenesis inhibitor with potent antitumor and antiangiogenic activity. Mol Cancer Ther 6:2012-2021. doi:10.1158/1535-7163.MCT-07-0193

2. Hamberg P, Verweij J, Sleijfer S (2010) Pre-)clinical pharmacology and activity of pazopanib, a novel multikinase angiogenesis inhibitor. Oncologist 15:539-547. doi:10.1634/ theoncologist.2009-0274

3. Sternberg CN, Davis ID, Mardiak J et al (2010) Pazopanib in locally advanced or metastatic renal cell carcinoma: results of a randomized phase III trial. J Clin Oncol 28:1061-1068. doi:10.1200/JCO.2009.23.9764

4. van der Graaf WT, Blay JY, Chawla SP et al (2012) Pazopanib for metastatic soft-tissue sarcoma (PALETTE): a randomised, double-blind, placebo-controlled phase 3 trial. Lancet 379:18791886. doi:10.1016/S0140-6736(12)60651-5

5. Suttle AB, Ball H, Molimard M et al (2014) Relationships between pazopanib exposure and clinical safety and efficacy in patients with advanced renal cell carcinoma. Br J Cancer 111:1-8. doi:10.1038/bjc.2014.503

6. Yu H, van Erp N, Bins S et al (2016) Development of a pharmacokinetic model to describe the complex pharmacokinetics of pazopanib in cancer patients. Clin Pharmacokinet. doi:10.1007/ s40262-016-0443-y

7. Deng Y, Sychterz C, Suttle AB et al (2013) Bioavailability, metabolism and disposition of oral pazopanib in patients with advanced cancer. Xenobiotica 43:443-453. doi:10.3109/00498254.2012.73 4642

8. Hurwitz HI, Dowlati A, Saini S et al (2009) Phase I trial of pazopanib in patients with advanced cancer. Clin Cancer Res 15:4220 4227. doi:10.1158/1078-0432.CCR-08-2740

9. Verheijen RB, Beijnen JH, Schellens JHM et al (2017) Clinical pharmacokinetics and pharmacodynamics of pazopanib: towards optimized dosing. Clin Pharmacokinet. doi:10.1007/ s40262-017-0510-z

10. Marin D, Bazeos A, Mahon FX et al (2010) Adherence is the critical factor for achieving molecular responses in patients with 
chronic myeloid leukemia who achieve complete cytogenetic responses on imatinib. J Clin Oncol 28:2381-2388. doi:10.1200/ JCO.2009.26.3087

11. Lewis JH, Kilgore ML, Goldman DP et al (2003) Participation of patients 65 years of age or older in cancer clinical trials. J Clin Oncol 21:1383-1389. doi:10.1200/JCO.2003.08.010

12. Mitchell AP, Harrison MR, Walker MS et al (2015) Clinical trial participants with metastatic renal cell carcinoma differ from patients treated in real-world practice. J Oncol Pract 11:491-497. doi:10.1200/JOP.2015.004929

13. Verheijen RB, Bins S, Mathijssen RHJ et al (2016) Individualized pazopanib dosing: a prospective feasibility study in cancer patients. Clin Cancer Res 22:5738-5746. doi:10.1158/1078-0432. CCR-16-1255

14. Herbrink M, de Vries N, Rosing H et al (2016) Quantification of 11 therapeutic kinase inhibitors in human plasma for therapeutic drug monitoring using liquid chromatography coupled with tandem mass spectrometry. Ther Drug Monit 38:649-656. doi:10.1097/FTD.0000000000000349

15. Wang Y, Chia YL, Nedelman J, Schran H (2009) A therapeutic drug monitoring algorithm for refining the imatinib trough level obtained at different sampling times. Ther Drug Monit 31:579-584

16. R Core Development Team (2016) A language and environment for statistical computing. R Found Statistical Computing, Vienna. https://www.r-project.org/
17. Food and Drug Administration. Center for Drug Evaluation and Research (2008) Pazopanib clinical pharmacology and biopharmaceutics review. https://www.accessdata.fda.gov/drugsatfda docs/nda/2009/022465s000_ClinPharmR.pdf. Accessed 17 Oct 2017

18. Glade Bender JL, Lee A, Reid JM et al (2013) Phase I pharmacokinetic and pharmacodynamic study of pazopanib in children with soft tissue sarcoma and other refractory solid tumors: a children's oncology group phase I consortium report. J Clin Oncol 31:3034-3043. doi:10.1200/JCO.2012.47.0914

19. Ornstein MC, Rini BI (2016) Pharmacokinetically-guided dosing of oral drugs: true precision oncology? Clin Cancer Res 22:56265628. doi:10.1158/1078-0432.CCR-16-1833

20. Beumer JH (2013) Without therapeutic drug monitoring, there is no personalized cancer care. Clin Pharmacol Ther 93:228-230. doi:10.1038/clpt.2012.243

21. Yu H, Steeghs N, Nijenhuis CM et al (2014) Practical guidelines for therapeutic drug monitoring of anticancer tyrosine kinase inhibitors: focus on the pharmacokinetic targets. Clin Pharmacokinet 53:305-325. doi:10.1007/s40262-014-0137-2

22. de Wit D, Guchelaar H-J, den Hartigh J et al (2015) Individualized dosing of tyrosine kinase inhibitors: are we there yet? Drug Discov Today 20:18-36. doi:10.1016/j.drudis.2014.09.007 